\title{
LA LEALTAD CUESTIONADA. ADSCRIPCIÓN POLÍTICA Y CONFLICTO DE AUTORIDAD EN LA REPRESENTACIÓN ESPAÑOLA EN EL PERÚ, 1933-1939¹
}

\author{
ASCENSIÓN MARTÍNEZ RIAZA \\ Universidad Complutense de Madrid
}

RESUMEN: Los estudios sobre las relaciones entre España e Iberoamérica durante la Segunda República y la Guerra Civil españolas (1931-1939) apenas introducen el caso del Perú. Este trabajo aborda aspectos inéditos a partir de la consulta de documentación de archivos españoles y peruanos. Por un lado se sitúa a los agentes diplomáticos y consulares y se sigue su trayectoria desde la lealtad a la República hasta la adbesión muy temprana al bando franquista; por otro se analiza la posición de elementos notables de la colonia española que igualmente se unieron a la causa nacionalista. Por fin se descubre cómo, tras los planteamientos ideológicos y el alineamiento político, se advierte una fuerte rivalidad por espacios de poder y por el ejercicio de la autoridad entre el jefe de la misión diplomática, el cónsul y sectores de la elite de la colonia organizada. La espiral de enfrentamientos afectó al funcionamiento de la diplomacia franquista en el Perú.

Palabras Clave: España. Perú. Diplomacia. Segunda República. Guerra Civil. Elite colonial española.

ABSTRACT: Existing studies of the relations between Spain and Latin America during Spain's Second Republic and Civil War (1931-1939) barely touch upon Peru. Certain aspects that until now have received no attention are analyzed in this essay, which is based on primary sources from Spanish and Peruvian archives. In the first place, the author looks at the behaviour of Spanish diplomatic and consular agents, revealing their initial loyalty to the Republic and their very early adhesion to Franco. Secondly,

1 Este trabajo es resultado del Proyecto de Investigación HUM2005-00610/HIST Haciendo Patria: gestión diplomática, sociedad y negocio en las relaciones de España con el Perú, 1/2 siglo XX, financiado por el Ministerio de Educación y Ciencia de España. Los argumentos que se presentan fueron debatidos en las III Jornadas de la Comisión Española de las Relaciones Internacionales celebradas en Burgos en octubre de 2004. 
important individuals among the more significant members of the Spanish colony in Peru also joined the nationalist cause. Finally, in addition to ideological and political factors, this article shows the intense rivalry for power and influence which developed between the chief of the diplomatic mission, and the most powerful men in the Spanish colony. This personal rivalry triggered a series of struggles for political and personal loyalties and effected the working of Francoist diplomacy in Peru.

KEY WORDS: Spain. Peru. Diplomacy. Second Republic. Spanish Civil War. Spanish elite in Peru.

\section{INTRODUCCIÓN}

Los estudios sobre las relaciones entre España y las repúblicas iberoamericanas durante la II República, la Guerra Civil y el primer franquismo, apenas introducen, cuando no obvian, el caso del Perúz. Son excepción las aportaciones de Davies y González Calleja que atienden ciertos aspectos de una realidad no por desconocida menos rescatable 3 .

Desde el restablecimiento definitivo en 1879 las relaciones oficiales entre el Perú y España no pasaron por alteraciones que las pusieran en riesgo. En cuanto al fondo, en el estado de la investigación se puede avanzar que, en líneas generales, tanto las relaciones diplomáticas como las económicas fueron de perfil bajo. Ninguno de los dos países tuvo peso para el otro en materia de política exterior, si exceptuamos los arbitrajes de la Corona y de la II República en conflictos del Perú con países vecinos (Ecuador y Chile, y la cuestión de Leticia con Colombia respectivamente) o el que España tomara a su cargo los asuntos de Alemania durante la Primera Guerra Mundial (Martínez Riaza 1996; Novack 2001). Otras prioridades ocupaban la agenda de los ministerios correspondientes: en el caso

2 Las líneas maestras de la política exterior de España en América Latina han sido el centro de dos investigaciones nucleares, la de TABANERA, N.: Ilusiones y desencuentros. La acción diplomática republicana en Hispanoamérica. Madrid, CEDEAL, 1996, para la II República y la de PARDO, R.: Con Franco hacia el imperio. La política exterior española en América Latina 1939-1945. Madrid, Universidad Nacional de Educación a Distancia, 1995, para el primer franquismo. Ambas han proporcionado el marco de referencia necesario para conocer el funcionamiento administrativo y los instrumentos de actuación, así como los proyectos y realizaciones.

3 Davies divide el trabajo en dos grandes apartados: la respuesta oficial a la Guerra Civil española y la valoración de intelectuales y políticos peruanos. Aborda la cuestión desde el Perú y utilizando fuentes peruanas, aunque no tuvo acceso al Archivo del Ministerio de Relaciones Exteriores, Davies, Thomas M. Jr. «Perú», en Mark FALCOFf y Frederick PIKE, The Spanish Civil War. American Hemispheric Perspectives. Nebraska University Press, 1982, pp. 203-243. González Calleja toma la referencia de Davies, para demostrar la escasa influencia que tuvo la Falange Española en la formación del fascismo peruano. Además de fuentes hemerográficas y de autores peruanos involucrados, incorpora las dos principales publicaciones de la colonia española, iArriba España! y iUnidad!, GonZÁlEZ CAllejA, Eduardo: «La derecha latinoamericana en busca de un modelo fascista: la limitada influencia del falangismo en el Perú (1936-1945)», Revista Complutense de Historia de América, (Madrid) 20 (1994), pp. 229-255. 
del Perú los conflictos interregionales y el acercamiento a la órbita de los Estados Unidos; en el de España, el norte de África y la difícil ubicación en un sistema internacional en cuyo tablero de ajedrez no era sino un peón más.

En el marco de una política oficial poco definida y ante la escasez de instituciones que establecieran elementos para el intercambio, fueron en ocasiones iniciativas personales las que impulsaron proyectos y actuaciones. Las redes familiares con ramas en ambos países funcionaron en situaciones dadas ${ }^{4}$, y fueron individuos los que gestionaron la formación de espacios elitistas de intercambio (Academia de la Lengua, Academia Nacional de la Historia, Sociedad Geográfica de Lima). Bajo el paraguas del acercamiento cultural se promovieron, tanto durante la última etapa de la Monarquía como durante la II República, algunos proyectos 5 . Fueron instrumentos fundamentales, primero la Oficina de Relaciones Culturales, creada por el Ministerio de Estado en 1921, y después la Junta de Relaciones Culturales, reformada en 1931, que quedó vacía de competencias y presupuestos tras la victoria del gobierno de centro derecha en las elecciones de noviembre de 1933. Tabanera en la obra citada ha procesado la cuantía y destino de las dotaciones presupuestarias durante la II República y hasta 1935 en los distintos países iberoamericanos en los que España tenía legaciones ${ }^{6}$.

Desde nuevos planteamientos metodológicos la historia de las Relaciones Internacionales trata de profundizar en el calado de los temas, sus causas, su gestación y su alcance, además de en los actores implicados y en las coordenadas espacio temporales, reformulando los supuestos de la historia diplomática dominante durante el siglo XIX que «se articulaba en un patrón caracterizado por la secuencia cronológica de los acontecimientos políticos y diplomáticos, que narra más que explica, y que se fundamenta científicamente en la objetividad del documento diplomático, principio y fin de la tarea del historiador» ${ }^{7}$.

4 España era un destino cotizado y por eso ocuparon la legación de Madrid miembros de familias importantes con vínculos, en ocasiones, con familias notables españolas. Es el caso de los Osma: Joaquín José de Osma fue el primer ministro plenipotenciario en 1880 y una de sus hijas contrajo matrimonio con Antonio Cánovas del Castillo; Juan de Osma fue el representante del Perú desde 1932 hasta la ruptura de relaciones en marzo de 1938.

5 Es el hilo argumental de las investigaciones de Delgado, Lorenzo: Imperio de papel. Acción cultural y Política Exterior durante el Primer Franquismo, Madrid, CSIC, 1992; SEPÚlVEDA MUÑOZ, Isidro: Comunidad cultural e hispano-americanismo, 1885-1936, Madrid, Universidad Nacional de Educación a Distancia, 1994; NiÑO, Antonio: "Orígenes y despliegue de la política cultural hacia América Latina», en L'Espagne, la France et L'Amerique Latine, Paris: L'Harmattan CSIC, 2001, pp. 25-163.

6 En el caso del Perú advierte que los gastos prácticamente se mantuvieron desde 1931 (66.000 ptas.) hasta 1935 (61.500). Otro tanto sucedió en los casos del Uruguay, Guatemala, El Salvador y Paraguay, mientras en otros países hay una notable disminución, sobre todo entre 1931 y 1933

PEREIRA, Juan Carlos: «La historia de las Relaciones Internacionales como disciplina científica». En Juan Carlos Pereira (coord.): Historia de las Relaciones Internacionales contemporáneas». Barcelona, Ariel, pp. 1-36/20. 
En cualquier caso la investigación histórica se sustenta en buena medida en los documentos, con lo que de «grandeza y miseria» hay en ello. Como otros, el espacio de las relaciones internacionales reserva un margen a lo desconocido, a lo que no se podrá recuperar. ¿Cuántas negociaciones y decisiones no se han planteado y tomado en conversaciones o encuentros desarrollados en espacios públicos o privados, sin que haya quedado registro de ellas? Las fuentes de carácter oficial y también personal (correspondencia, memorias, ensayos), son generadas por actores que muestran unas caras de la realidad y ocultan o disfrazan otras, y eso en los casos «afortunados» en los que se cuenta con bases documentales suficientes, localizadas y ordenadas como para permitir la reconstrucción de situaciones y dinámicas. El itinerario del historiador tiene un curso zigzagueante, con vías que se cierran o no llevan a ninguna parte. La información no está siempre donde "por lógica» debería estar o simplemente no está.

Ésa es, en parte, la historia de la historia de las relaciones oficiales entre España y el Perú durante la II República y la Guerra Civil españolas. En el estadio actual de la investigación la disponibilidad de la documentación pone unos límites que condicionan las posibilidades de desentrañar algunas cuestiones fundamentales. Para el marco cronológico en que se mueve la propuesta han resultado más generosos los fondos peruanos, léase Archivo del Ministerio de Relaciones Exteriores, donde se encuentra relativamente ordenada y completa la documentación generada por los encargados y ejecutores de la política bilateral. A ella se unen las publicaciones oficiales (memorias de ministros y boletines del Ministerio) así como la correspondencia y obra escrita por diplomáticos e intelectuales implicados ${ }^{8}$. Los repertorios españoles son más discontinuos y precarios, situación a la que no es ajena el proceso de los caminos que se bifurcan en julio de 1936, cuando la cúpula de la legación española (ministro y secretario) y el cónsul en Lima presentaron su dimisión al gobierno de la República y se adhirieron de inmediato a la Junta de Burgos actuando desde entonces como agentes oficiosos. La representación mexicana se haría cargo de los asuntos de la República hasta la ruptura de relaciones entre el gobierno de Negrín y el de Benavides en marzo de 1938.

Para avanzar en algunas líneas de una situación poco conocida se presentan ahora algunas piezas de un puzzle, todavía incompleto, en el que se barajan como elementos fundamentales para el análisis:

1. Desentrañar la posición y actitudes de los agentes de la política española en el Perú, tanto del jefe de la legación como del cónsul en Lima, que

8 Sólo a modo de ejemplo y por su relación con la propuesta se puede mencionar a Jorge BAILEY LEMBCKE, destacado a Madrid para gestionar el asunto de los asilados en el Consulado del Perú. Ver Recuerdos de un diplomático peruano 1917-1954, Lima, Mejía Baca, 1959, pp. 125-145; o la correspondencia de José de la Riva Agüero con españoles, en parte editada en sus obras completas por el Instituto Riva Agüero de la Pontificia Universidad Católica del Perú, y en parte en su archivo personal. 
apenas conocido el alzamiento militar dimitieron ante el gobierno de la República y reconocieron como autoridad superior al Generalísimo Franco, actuando desde entonces como sus agentes oficiosos.

2. Introducir el comportamiento de sectores de la elite de la colonia española, organizada en tres asociaciones básicas: la Sociedad Española de Beneficencia de Lima (SEBL), el Casino Español y la Cámara Oficial Española de Comercio del Perú (COECP) ${ }^{9}$. Fue la junta directiva de la SEBL la que presentó una postura más beligerante defendiendo su autonomía histórica frente a injerencias externas.

3. Plantear los entresijos (hasta ahora inéditos) del enfrentamiento que se engendró en el seno de la representación entre el ministro Luis Avilés y Tiscar y el cónsul Antonio Pinilla Rambaud.

4. Situar el conflicto que se generó por espacios de poder, en el que ambos tomaron posiciones. En el trasfondo, la pugna entre miembros arraigados de la colonia española y hombres nuevos que coparon puestos utilizando los instrumentos de la política franquista, especialmente la Falange Española y las JONS.

\section{LOS AgeNTES DE LA POlítica OfiCial ESPAÑOla EN EL PeRÚ.}

El acercamiento e intensidad de los intercambios bilaterales entre el Perú y España durante el Oncenio y la Dictadura de Primo de Rivera, se ralentizaron a comienzos de la década de 1930 (Martínez Riaza 1994). En España el triunfo de la candidatura republicana en las urnas el 14 de abril de 1931 abriría una etapa convulsa. El cambio fue liderado por hombres y fuerzas de trayectoria y propósitos heterogéneos lo que dificultó las posibilidades de articular y llevar a la práctica programas políticos, sociales y económicos. Las elecciones generales de noviembre de 1933 modificaron el espectro político al imponerse las formaciones de centro derecha, que no trajeron la estabilidad. Las movilizaciones de la oposición alcanzaron momentos álgidos en octubre de 1934 con los levantamientos de Cataluña y de Asturias. Las maniobras del ejecutivo presidido por Lerroux, no detuvieron el progreso de las fuerzas de izquierda que coaligadas en el Frente Popular ganaron las elecciones de febrero de 1936. De nuevo desacuerdos internos a los que se sumaron la fuerte presión exterior llevaron a una situación crítica en la que los militares ganaron protagonismo. En julio de 1936 Francisco Franco encabezaría la sublevación que enfrentaría a las dos Españas en la Guerra Civil.

Con la sublevación militar se abrió en la representación oficial y en ciertos sectores de la colectividad española en el Perú una encrucijada a la que hay que

9 La SEBL se fundó en 1857 y es la más antigua de las organizaciones de españoles en el Perú republicano. El Casino Español se constituyó en 1880 y la COECP en 1887. 
aproximarse teniendo en cuenta unas coordenadas, las del gobierno de Óscar Benavides, que no son inocuas. El general estaba por convicción y praxis lejos de las alternativas de izquierda y sus afinidades con el bando franquista eran más que notables. Fue presidente provisorio por designación del Congreso de 30 de abril de 1933, tras el asesinato de su predecesor Luis Miguel Sánchez Cerro. Según el orden constitucional vigente, en junio de 1936 se convocaron elecciones generales que se celebrarían en octubre (en el intervalo se producía en España el alzamiento militar). La victoria del candidato apoyado por la Alianza Popular Revolucionaria Americana (APRA) movilizó a los sectores conservadores y el Congreso tomó cartas prorrogando durante tres años el mandato de Benavides. Pasado este tiempo, el 8 de diciembre de 1939 entregaba el testigo a su sucesor el civil Manuel Prado que le envió como representante a Madrid ${ }^{10}$.

Tanto Davies (1982: 218-220) como González Calleja (1994a: 235) establecen interesantes elementos de comparación, tanto a nivel personal como de actuación política, entre Benavides y Franco. Habría que añadir que el gobernante peruano conoció de primera mano la realidad española, ya que fue representante en Madrid en dos ocasiones: la primera designado por la Junta Militar presidida por el coronel Luis Miguel Sánchez Cerro (Resolución de 3 de octubre de 1930), se hizo cargo el 7 de enero de 1931, estuvo al frente de la legación al proclamarse la República y se mantuvo hasta que fue nombrado ministro plenipotenciario en Londres (27 de febrero de 1932). La segunda después de dejar la presidencia, con rango de embajador y por designación del gobierno de Manuel Prado (27 de enero de 1940), permaneció en el puesto hasta el traslado a la Argentina (nombramiento de 14 de marzo de 1941).

No se ha localizado ningún trabajo que con propósitos generales atienda a la gestión de la representación española en las repúblicas latinoamericanas en esta coyuntura compleja, que caracterice socio profesionalmente a sus miembros y calibre su gestión; que evalúe la relación entre los diplomáticos y los cónsules cuyas competencias se solapaban y, como en este trabajo se muestra, se interferían; que haga un seguimiento de las hojas de servicio para rastrear cuales fueron los destinos americanos — muchos pasaron por las legaciones de distintas repúblicas - y cómo fueron percibidos por los interesados. En líneas generales Lima no era considerado como un destino cotizado, más bien los designados entendían que era un paso «obligado» en una carrera con otras metas, por lo que bastaba con «cubrir el expediente» ${ }^{11}$. Y desde luego hay que singu-

${ }^{10}$ Durante el mandato de Benavides se continuó la tendencia autoritaria y modernizadora desarrollada por el gobierno civil de Leguía (1919-1930), aunque ahora bajo la alianza entre militares y oligarquías civiles perseguidas durante el Oncenio. Como Franco, siguió un patrón de paternalismo en política social aplicando medidas de bienestar al tiempo que reprimía la disidencia. La trayectoria autoritaria y modernizadora del Perú ha sido el hilo argumental de HerBold, Carl: Development in the Peruvian Administrative System 1919-1939. Modern and Traditional Qualities in Government under Autoritarian Regimes, Michigan, Yale University, Ann Arbor, 1974, pp. 136-144.

11 El trabajo de SEPúlvedA MuÑOZ, Isidro: «Diplomáticos y cónsules españoles en América, 1892-1936». Espacio Tiempo y Forma, Serie V, Hª Contemporánea, T.V. (Madrid), UNED, 1992, 
larizar a los funcionarios activos, preocupados por hacer eficazmente su trabajo, potenciar líneas de intercambio, establecer contacto con la población española y vincularse con los círculos de poder local ${ }^{12}$.

Cuando se proclamó la II República era ministro plenipotenciario de primera clase en el Perú Joaquín Carrillo de Albornoz, marqués de Faura. Incómodo con la situación, a comienzos de 1932 solicitaba primero el traslado, y después una licencia que le permitiría abandonar Lima el 4 de mayo. Ya no regresaría ${ }^{13}$. Le sucedió un ministro político, Antonio Jaén y Morente, en el cargo desde marzo de 1932 hasta septiembre de 1933, preocupado por recuperar el tiempo perdido por Carrillo de Albornoz y que desplegó una intensa actividad propagandística acerca de las bondades de la República, especialmente en el ámbito de lo social y cultural (misiones pedagógicas) ${ }^{14}$. Su experiencia en el Perú quedaría recogida en La Lección de América (1934) que transmitía tranquilidad en el seno de la colonia española, ponderaba la labor del cónsul Pinilla y valoraba los gestos de amistad hacia la República por parte del gobierno de Benavides.

Luis Avilés y Tiscar, ministro de tercera clase, llegó a Lima para hacerse cargo de la legación en diciembre de 1933 procedente de Caracas. Licenciado en Derecho por la Universidad de Madrid, amplió estudios en el Colegio Mayor de los Españoles de Bolonia donde se doctoró. Ingresó por oposición en el cuerpo diplomático en 1913 y prestó servicio en las legaciones de Berna, Quirinal, Londres, Copenhague, Santa Sede, Oslo y Berlín, además de en la Comisaría de Marruecos del Ministerio de Estado. Permaneció en Lima hasta mayo de 1939 en que partió a Bogotá (Colombia) en representación del gobierno de Franco. No se ha localizado su Expediente Personal en el AMAE, pero su nombramiento fue firmado por el gobierno de centro derecha salido de las elecciones de noviembre de 1933.

Antonio Pinilla Rambaud es pieza clave del engranaje de la política de España en el Perú. Fue cónsul en Lima desde enero de 1918 hasta que, también

pp. 397-412, no mantiene correspondencia entre un título ambicioso y unos contenidos escasos y muy genéricos.

${ }^{12}$ No hay más que comparar en el Archivo del Ministerio de Asuntos Exteriores de España (AMAE) la correspondencia que mantienen los distintos ministros con el Ministerio de Estado para distinguir entre aquéllos que se quedaban en asuntos de trámite y los que aprovechaban la participación en la vida política y social para introducir o reactivar asuntos. El tratamiento que dan a la colonia española es otro de los elementos diferenciadores.

13 Nombrado por RD de 8 de julio de 1930 tomó posesión el 1 de enero de 1931. El Expediente personal detalla los pormenores de la contrariedad del ministro ante una situación que le pillaba a tras mano, y le obligaba a ejecutar actos simbólicos (cambio de bandera, supresión de imágenes del Rey) que no compartía. Hasta abril de 1931 firmaba los documentos como marqués de Faura, después lo haría como Joaquín Carrillo de Albornoz. Ver AMAE P343 Exp. 24. 299.

14 Fue elegido diputado a Cortes Constituyentes por Córdoba en las elecciones de 28 junio de 1931 representando a la Derecha Liberal Republicana. En la coalición del Frente Popular de nuevo sería diputado por Córdoba, esta vez vinculado a Izquierda Republicana. Renunció a su puesto en el Perú tras la dimisión de Azaña (8 de agosto 1933). AMAE P. 313 Exp. 22.517. 
por orden de Franco de 4 de febrero de 1939, fue trasladado a La Paz (Bolivia) donde murió el 3 de abril, dos días después de una victoria que no pudo celebrar. Fueron veinte años al frente del Consulado, un periodo de tiempo excepcionalmente largo en un destino de representación oficial. Ocupó una posición de privilegio desde la que pudo conocer a fondo el funcionamiento de la legación, mientras sus componentes cambiaban (coincidió con cinco ministros) él permanecía alentando la continuidad de asuntos y relaciones. Entendió que la cultura era un instrumento político de primera magnitud y participó en los distintos acontecimientos que afirmaban la presencia de España. Sus orígenes intelectuales le vinculaban a Rafael Altamira, que fue quien le introdujo en los círculos hispanistas limeños entregándole una carta de presentación para José de la Riva Agüero. En ellos se movió y está registrada su presencia en la fundación del Mercurio Peruano, la revista cultural iniciada por Víctor Andrés Belaunde en 1918. Conoció como nadie la situación de los españoles, potenció las asociaciones en que se organizó la colonia y estableció fuertes vínculos con algunos de sus miembros más notables, esgrimiendo su defensa frente a las injerencias de Avilés. Arraigó en la sociedad peruana a través del matrimonio con la actriz y escritora María Isabel Sánchez Concha conectada con la elite peruana y que llegado el momento trabajó decididamente a favor de la causa nacionalista ${ }^{15}$.

\section{TODOS ERAN «NACIONALISTAS». EL ALINEAMIENTO POLÍTICO DE LA REPRE- SENTACIÓN OFICIAL Y DE LA ELITE DE LA COLONIA.}

El alzamiento militar se tradujo en una bicefalia que afectó al servicio exterior de España y los dos bandos se aprestaron reorganizar el cuerpo diplomático y consular (Pardo 1995: 21-45). El 24 de julio de 1936 la República emitía una orden circular requiriendo a todos los jefes de misión y encargados de negocios que mandaran un telegrama confirmando su lealtad. Se recibieron 128 adhesiones y 59 dimisiones, entre ellas las del ministro (Avilés y Tiscar), el secretario (Guillén) y el cónsul (Pinilla Rambaud) de España en el Perú. Los tres se adherirían a la Junta Nacional de Burgos, en respuesta a su llamado de 28 de julio ${ }^{16}$.

El impacto de estos cambios diplomáticos en la sociedad peruana fue escaso, aunque los principales medios de expresión se hicieran eco de la nueva si-

15 La gestión consular de Pinilla ha sido presentada en la ponencia «Funcionarios españoles en la repúblicas americanas. El Consulado de España en el Perú 1919-1939». XI Congreso de la Asociación Española de Americanistas. Murcia, septiembre 2004.

16 Marina Casanova (1996: 241-258) menciona sus nombres pero no da las referencias precisas (no es exacto que Pinilla dejara de acatar a la República el 8 de enero de 1936). Acude a los telegramas que se encuentran en el AMAE RE 152-155. En el seguimiento de la doble carrera diplomática que despliegan la República y la Junta de Defensa Nacional de Burgos, el Perú pasa inadvertido. 
tuación española. El Comercio, que se decantaría por la causa nacionalista, insertaba el primero de agosto una nota explicativa,

Se nos proporciona copia de la renuncia que de sus respectivos cargos han hecho los señores Luis Guillén, consejero de la Legación de España, y Antonio Pinilla, cónsul de la misma nacionalidad en Lima. Ambos funcionarios se solidarizan con los fundamentos de la presentada por el ministro Sr. Avilés y Tiscar y que hemos publicado en una de nuestras anteriores ediciones. Dicha renuncia dice textualmente: Ministro de Estado. Madrid. Identificados con jefe ministro Sr. Avilés, rogamos acepte vuecencia nuestras renuncias. Luis Guillén consejero, Antonio Pinilla, cónsul de España ${ }^{17}$.

El principal diario del Perú siguió muy de cerca y con mucha intensidad el proceso español, y el curso de la guerra fue noticia de primera plana, advirtiéndose una basculación progresiva desde la consideración del alzamiento como un levantamiento contra el gobierno legítimo al apoyo de las posiciones franquistas. Las noticias de agencia se completan con artículos de opinión, algunos de ellos firmados por españoles residentes en Lima (Luis Fábrega que había sido agente de la Casa de América de Barcelona). Ni El Comercio, ni los otros periódicos de gran tirada de Lima, La Prensa y La Crónica entran apenas en los asuntos internos de la legación y el consulado ni en los movimientos que se producen en el seno de la colonia española ${ }^{18}$.

De inmediato, el 31 de julio de 1936, para cubrir el vacío una vez que Avilés fue separado del cuerpo diplomático de la República ${ }^{19}$, el ministro de Estado Augusto Barcia pedía al ministro del Perú en Madrid Juan de Osma que comunicara al responsable de Relaciones Exteriores Alberto Ulloa que se haría cargo de los intereses republicanos, en calidad de encargado de negocios «ad interim», el ministro plenipotenciario en Panamá Juan de Arenzana y Chinchilla. Apenas un mes más tarde, el 27 de agosto, Arenzana visitaba a Ulloa para comunicarle que también acataba a la Junta de Burgos ${ }^{20}$. Tras unos meses de consulta los asuntos de la República pasaron a ser gestionados por la representación de México.

17 El Comercio. Lima, sábado 1 de agosto de 1936, p. 3.

18 Davies, «Perú» basa en buena parte su interpretación en el análisis de contenidos de periódicos que se suman a uno u otro bando, entre ellos El Comercio. Pinto Gamboa apenas puntea algunas muestras de tres de los periódicos de mayor tirada de Lima, El Comercio, La Prensa y La Crónica. Incorpora una selección de notas que tienen que ver con acontecimientos relacionados con la situación de España que se producen tanto en la península como en el Perú, PINTO GAMBOA, Willy: Sobre fascismo y literatura (la Guerra Civil española en La prensa, El Comercio y La Crónica), Lima, Cibeles, 1983.

19 Archivo Histórico Guerra Civil. Salamanca. Secretaría Exp. 39.759, Leg.2665. PS Madrid, fol.6. Madrid, 30 de julio de 1936.

20 Archivo del Ministerio de Relaciones Exteriores del Perú, Legación del Perú en España, 1936, 5-13/22. Los documentos se publican en el Boletín Ministerio Relaciones Exteriores del Perú, año XXIII, CXXXV, tercer trimestre 1936. Lima, Empresa Editorial Peruana, 1936, pp. 133-135. 
Del otro lado, el 26 de julio de 1936 Ulloa recibía un telegrama de Miguel Cabanellas, presidente de la Junta de Defensa Nacional de Burgos, comunicándole su formación y expresando el deseo de conservar las amistosas relaciones que siempre habían unido a ambos países. Pero la Cancillería no respondió en cumplimiento del principio internacional de no intervención y por la necesidad de proteger los intereses de los ciudadanos peruanos ${ }^{21}$. Benavides continuó pues manteniendo relaciones con el gobierno legítimo, pero permitió que la representación nacionalista siguiera actuando desde las sedes de Barranco (Legación) y de Malambito (Consulado), y que tuvieran validez legal los documentos que emitían. El estatuto de agentes oficiosos les obligaba a una extremada prudencia, tenían órdenes de respetar las leyes y a las autoridades del país y no complicar aún más la situación de estado no reconocido.

La situación anómala no mereció especial atención por parte de los medios peruanos, ni siquiera de CADRE y España Libre, auspiciados por intelectuales pro republicanos, que en su corta y precaria trayectoria concentraron sus esfuerzos en atacar al fascismo en ascenso que tenía en Franco y Benavides a dos representantes cualificados, sin entrar en los asuntos del día a día que afectaban a la legación y a la colonia españolas ${ }^{22}$. Sólo $C A D R E$ dedicaba una nota denunciando la situación anómala que suponía el que Avilés, «ex encargado de negocios de España y traidor a su patria y a su gobierno", se permitiera actuaciones prevaricadoras,

Ex encargado de negocios de España y traidor a su patria y a su gobierno. Este individuo vergüenza de la colonia española, gracias al amparo que le presta la dictadura de Benavides, está cometiendo una serie de tropelías contra los intereses de la España Republicana en nuestro país. No sólo permanece indebidamente en la legación, sino que pretende con cinismo desigual y con audacia de pájaro de alto vuelo hipotecar el local que ella ocupa por la suma de 50.000 ptas. ${ }^{23}$.

21 Memoria del Ministro de Relaciones Exteriores del Perú D. Alberto Ulloa. Comprende desde el 13 de abril al 22 octubre de 1936. Lima, Imprenta Torres Aguirre, 1936, p. LXXIII-LXXIV. El ministro hace también la secuencia de los acontecimientos: el 30 de julio Avilez (sic) le comunicaba que se había puesto a las órdenes de la Junta de Defensa, el $1^{\circ}$ de agosto el Ministro de Estado del gobierno de Madrid le rogaba que aceptara como Encargado de Negocios ad-interim al ministro en Panamá Arenzana que llegó a Lima el 19 de agosto y que en su primera visita el día 27 de agosto le comunicaba su acatamiento a la Junta de Burgos. Durante meses las relaciones diplomáticas se mantuvieron únicamente a través de la representación peruana en España (p. LXXV).

22 Se han revisado tres números de CADRE, de octubre de 1936 a julio de 1937 en la Biblioteca Nacional del Perú. Las colaboraciones no están firmadas y predominan los ataques a la prensa burguesa de Lima, especialmente a El Comercio, y las diatribas contra el fascismo internacional. España Libre, órgano del comité local de los «amigos de la República española» adherido a la «CADRE», se acerca a la situación de los frentes de batalla en España y a la lucha de los intelectuales de todo el mundo contra el totalitarismo. En los tres números consultados (28 de junio a 17 de julio de 1937) no hay ninguna alusión a lo que se está gestando en la representación española ni al alineamiento de los españoles.

23 CADRE, Boletín del Comité de Defensores de la República Española, 3. Lima, julio de 1937, p. 3, sin firma. La sede de la legación de España en Barranco fue un obsequio del gobierno de Leguía. 
La ruptura diplomática del Perú con la II República el 17 de marzo de 1938 sería el final de una cadena de desacuerdos profundos y de incidentes que ganaron en importancia. El detonante fue la cuestión de los asilados peruanos y españoles que encontraron refugio en el Consulado del Perú y que el presidente Benavides justificó en el mensaje anual ante el Congreso ${ }^{24}$. Coincidía en el tiempo con el punto álgido del enfrentamiento entre el ministro Avilés y el cónsul Pinilla que se desataba, como se verá, el 11 de marzo.

En agosto de 1936 se abría un período confuso, tanto por la intermitencia de la documentación que los funcionarios «desafectos» enviaban a Burgos, como porque fue tomando cuerpo una urdimbre de enfrentamientos en la que estuvieron involucrados de un lado Avilés, y del otro el cónsul Pinilla y algunos hombres fuertes de la colonia, que controlaban desde hacía tiempo las instituciones y se oponían a injerencias externas o, lo que era lo mismo, a ceder parcelas de poder. Además entrarían en escena nuevos actores, españoles llegados ya entrado el siglo XX y que, dedicados fundamentalmente a actividades comerciales, no lograron despegar económicamente. La política sería el medio al que acudirían para afirmarse socialmente. Hombres como Manuel Morales, que apostaría hasta el final por la Junta Nacionalista, o Herminio Santibález que sería el delegado de la Falange, contestaron desde esta cobertura la autoridad del «patriarca» Aurelio Díaz Ufano, durante muchos años en la cúpula de la COECP y ahora de la SEBL. Con la excepción de Santíbañez ninguno tenía capacidad para elaborar discursos, de ahí que los argumentos que emplearon para hacerse valer y descalificar al contrario sean muy escasos y se circunscriban a documentos de carácter privado.

En esta propuesta se pone de manifiesto cómo, tras las declaraciones de lealtad primero a la Junta de Burgos y desde el 30 de enero de 1938 al gobierno presidido por Franco, se dirimían duras rivalidades por el control del poder y el ejercicio de la autoridad. Hay que tener en cuenta que los espacios en los que se movían eran reducidos y los encuentros e interferencias inevitables, por lo que los circuitos de amistad e intereses funcionaron en distintas direcciones.

La posibilidad de situar e interpretar algunos de los elementos de la confusión ha venido dada por la incorporación, entre otros, del Expediente Personal de Antonio Pinilla, los documentos del archivo privado de Valls i Taberner, miembro de la Embajada Nacionalista latinoamericana (Martínez Barrios 1998), los fondos del Casino Español y de la SEBL, y los testamentos y expedientes sucesorios de algunos españoles significados. Por su carácter minoritario la colonia no contó apenas con prensa propia. Se ha acudido a los tres únicos medios editados, el Boletín de la Cámara Oficial Española de Comercio del Perú/Mercurio (abril 1921-mayo 1935)25, iArriba España!, de la Junta Naciona-

24 Mensaje presentado al Congreso del Perú por el Sr. General de División Don Óscar R. Benavides, Presidente constitucional de la República. Lima, Talleres Gráficos, 1939, pp. 21-22.

25 La publicación oficial comenzó a editarse en abril de 1921. A partir del número 48 de junio de 1932 cambió su denominación por la de Mercurio. El último número que se editó es el 59, de 1935. 
lista del Perú (noviembre 1937-julio 1938), y iUnidad! órgano de la Falange y las JONS (julio 1938-julio 1941), fundamentales para la reconstrucción de las relaciones bilaterales, y sobre todo de la dinámica al interior del colectivo de los españoles ${ }^{26}$.

Avilés, Pinilla, y los miembros de las juntas directivas de las tres principales instituciones eran gente de orden. Acataron la autoridad de los gobiernos que se sucedieron tras las elecciones de abril de 1931 y, al menos públicamente, no expresaron desacuerdos. Y eso aun cuando los gobiernos republicanos desatendieron progresivamente sus asuntos, de manera ostensible a partir de 1935 en que incluso dejó de publicarse (por falta de subvenciones) el Mercurio de la Cámara Oficial Española de Comercio del Perú. Pero, en su criterio, una cosa era la República y otra el caos y la subversión marxista. La participación de los comunistas en el Frente Popular que ganó las elecciones de febrero de 1936 era más de lo que podían aceptar. El alzamiento militar de julio fue el catalizador para que se manifestaran opciones, quién sabe cuanto tiempo latentes, y la Junta de Burgos se presentó como la alternativa en torno a la cual alinearse.

La fractura de las dos España tras el alzamiento militar de julio de 1936 se reprodujo en el Perú, aunque sin alcanzar la virulencia que en otras repúblicas latinoamericanas, tales como Cuba, la Argentina y $\mathrm{México}^{27}$. Las principales

26 En el proceso de la investigación ha llamado poderosamente la atención la dificultad para acceder a esta prensa de la colonia, cuya tirada se desconoce, pero que en cualquier caso debió distribuirse entre instituciones oficiales y suscriptores. Se ha consultado la colección completa del Boletín de la Cámara Oficial Española de Comercio del Perú/Mercurio a partir de los ejemplares de la Hemeroteca Municipal de Madrid y la Fundación Figueras, Pavelló de la República, Universitat de Barcelona. iUnidad!, órgano de las FET y de las JONS, se conserva íntegramente también en la Hemeroteca Municipal de Madrid. El caso de iArriba España! de la Junta Nacionalista es diferente, su búsqueda en los más diversos repertorios del Perú y España ha resultado infructuosa y sólo se han localizado tres números en la Hemeroteca Municipal de Madrid, del total de nueve que se publicaron (noviembre de 1937 a julio de 1938), según testimonio de su promotor Manuel Morales en carta a Valls i Taberner de 6 de agosto de 1938, MARTíneZ BARrIOS, Elena: Epistolario de la Embajada Nacionalista Latinoamericana: 1937-1938 (análisis histórico politico e institucional). Zaragoza, Universidad de Málaga, 1998, pp. 169-170.

27 NARANJo Orovio, Consuelo: Cuba, otro escenario de lucha. La guerra civil y el exilio republicano. Madrid, CSIC, 1998; QuiJadA, Mónica: Aires de República, aires de Cruzada: la Guerra Civil española en Argentina. Barcelona, Sendai, 1991; Montenegro, Silvina: La Guerra Civil española y la política argentina. Tesis Doctoral, Universidad Complutense de Madrid, 2002; LIDA, Clara E. (comp.): México y España en el primer franquismo, 1939-1950. Rupturas formales, relaciones ofciosas, México, El Colegio de México, 2001. Es interesante el paralelismo con el caso de la República de Chile trazado por VARgas, Juan Eduardo, Juan Ricardo COUYOUMdjIAN y Carmen Gloria DuHART: España a través de los informes diplomáticos chilenos, 1929-1939. Santiago de Chile, Ministerio Relaciones Exteriores de Chile, Instituto de Historia de la pontificia Universidad Católica de Chile, Consejo Superior de Investigaciones Científicas de España, Editorial Antártica, 1994; GARAY VerA, Cristian y Cristina Medina VALVerde: «La Guerra Civil española y Chile (1936-1939). Relaciones Internacionales e imágenes políticas» en Cuadernos de Historia de las Relaciones Internacionales, 2, CEHRI, Madrid, 2001, pp. 39-93 y más recientemente SAPAG, Pablo: Chile, frente de combate de la 
razones hay que buscarlas, además de en el orden establecido por el régimen de Benavides y en la ausencia de grandes temas en curso que ocuparan la agenda de las relaciones bilaterales, en el número reducido de españoles, unos 3.000 según estimaciones del Consulado, que se concentraban mayoritariamente en $\operatorname{Lima}^{28}$.

La colonia española, entendida como el conjunto de aquellos que se sentían unidos por lazos de identidad colectiva con España y se asociaban en agrupaciones específicas, no mostró gran beligerancia. La mayoría se adheriría a la causa franquista sin mayor compromiso, ya que su preocupación real estaba en el desarrollo de las actividades económicas y, a pesar de mantener la nacionalidad, se movía cotidianamente en los circuitos de la sociedad receptora. Los republicanos confesos y militantes eran contados, y no presentaron un frente común ${ }^{29}$.

\section{LAS SENDAS DEL LABERINTO. LAS ARISTAS DEL CONFLICTO ENTRE EL JEFE DE LA LEGACIÓN, EL CÓNSUL EN LIMA Y ELEMENTOS SIGNIFICADOS DE LA COLONIA.}

El ministro Avilés irrumpió como un elemento de distorsión en un escenario relativamente apacible. De talante autoritario, impuso las normas jerarquizadas que funcionaban en el mundo diplomático, incursionando e interfiriendo en espacios de poder que estaban configurados desde hacía tiempo. El choque con los miembros de la colonia que los controlaban se hizo inevitable y cristalizó en el enfrentamiento con Aurelio Díaz Ufano, uno de los hombres fuertes

guerra civil española. Valencia, Centro Tomás y Valiente-UNED, 2003 y ALMONACID, Fabián: «Españoles en Chile: reacciones de la colectividad frente a la República, Guerra Civil y Franquismo", Revista Complutense de Historia de América, 30 UCM, 2004, pp. 194-185. Los dos últimos se detienen en los comportamientos de la colectividad española en unas coordenadas diferentes a las que se daban en el Perú por cuanto los gobiernos de Alessandri y Aguirre Cerda fueron más abiertos y la presencia y organización de los republicanos fue mucho mayor.

28 El primer censo nacional de 1876 arrojaba una cifra total de 1.699 residentes en el país, que apenas había crecido según el segundo de 1940, que los tasaba en 2.478. En el intervalo entre los dos censos nacionales se realizaron recuentos regionales que permiten completar, en parte la secuencia. Para la provincia de Lima, el censo de 1920 cifraba en 1.006 en número de españoles, el de 1931 en 1.376 y el de 1940 en 1.197. Son los datos a manejar porque los esfuerzos del cónsul Pinilla para hacer un registro de españoles no se vieron coronados por el éxito. Ver, Manuel Atanasio FuENTES: Resumen del censo general de habitantes del Perú hecho en 1876. Lima, Imprenta del Estado, 1878; Perú. Dirección Nacional de Estadística, Censo Nacional de Población y Ocupación 1940. Lima, 1944; Perú. Junta Departamental de Lima Pro-desocupados. Censo de las Provincias de Lima y Callao, 1931. Lima, Imprenta Torres Aguirre, 1933.

29 Entre los que sí trabajaron a favor de la II República estuvieron el periodista José Pardo Castro, Eloy Monzón de la Asociación Cultural Republicana, y el médico Enrique Villanueva Valcarce, autor de Por el Prestigio de España en América (Lima, Librería Coriart, 1933), muy beligerante pero que aparece después haciendo donativos a la causa nacionalista. 
que había llegado al Perú con el siglo para dedicarse a actividades comerciales y lograría integrarse en los círculos de poder económico. Fue gerente y principal accionista de la Sociedad Anónima Grandes Molinos del Perú, vicepresidente de la Sociedad Nacional de Industrias, miembro de la Asociación de Propietarios de Lima, y durante muchos años (1924-1965), director del Banco Italiano (después Banco de Crédito). Presidió el Casino Español (1918 y 1926), la COECP (1923-1927) y la SEBL - con intermitencias - $(1933 \text { a 1945) })^{30}$.

El conflicto se trasladó al escenario de la SEBL, que Díaz Ufano presidía, y adquirió trascendencia cuando la Junta Directiva se negó reiteradamente en 1935 y en 1936 a participar, como le exigió Avilés y Tiscar, en los actos de celebración de aniversario de la República, aduciendo que la institución nunca había tomado parte en asuntos políticos. Si en la primera ocasión el incidente no revistió mayores consecuencias, en 1936 Avilés, todavía fiel a la República, elevó una protesta formal,

La entidad intitulada Sociedad Española de Beneficencia ha sido el único de los centros españoles que, no sólo no ha tenido a bien asistir ni enviar un representante al banquete celebrado por la colonia española sin distinción de matices el 14 de abril, sino que tampoco se ha dignado enviar ningún representante al recibimiento celebrado en la Legación de España con motivo del aniversario de las instituciones republicanas y del día nacional de nuestro país. Por muy independiente que sea esta entidad a la que me dirijo, y por individualista que sea también el concepto que forman sus componentes de las obligaciones de dicha entidad, existen sin embargo normas fijas y elementales de cortesía ineludibles para las instituciones que se denominan españolas en el extranjero ${ }^{31}$.

El envite se resolvería en primera instancia a favor del ministro y de resultas Díaz Ufano presentaría la renuncia irrevocable a la presidencia. Sería una decisión temporal, ya que retomaría las riendas en abril de 1937. Cuando en 1938 se reproducía el enfrentamiento Avilés ya no era el ministro leal a la República sino representante oficioso de la Junta de Burgos.

En el epicentro de la trama se situó el cónsul Pinilla que se movería en terreno resbaladizo. Por un lado era un funcionario respetuoso con la norma que tenía clara la obediencia debida a su superior, en este caso Avilés; por otro, por su larga permanencia en el Perú había establecido sólidas relaciones con miembros notables de la colonia, y Aurelio Díaz Ufano pertenecía a su círculo de amigos.

30 Había nacido en Ocaña (provincia de Toledo) el 27 de julio de 1881 y moriría en Lima el 12 de mayo de 1965. Llegó al Perú en 1900 y lograría ser reconocido y admitido en los círculos más selectos de la sociedad peruana. Fue durante años «el patriarca» de la colonia española. Para componer su trayectoria se ha acudido a muy diversas fuentes de repertorios peruanos, entre ellas el Expediente Sucesorio en el que se enumeran y valoran sus bienes (Archivo General de la Nación. Perú (AGN), ASL, 38845).

31 Acta de Sesiones de la SEBL, 18 de abril de 1936. 
Estos serían los vértices del conflicto que se intensificaría en una espiral que fue ganando en complejidad a medida que se sumaban nuevos elementos. Para seguir la dinámica se han tomado situaciones en las que las posiciones se enconaron y quedaron patentes las tensiones existentes aún antes del inicio de la guerra civil. En primer lugar la orden de Avilés de comienzos de agosto de 1936 conminando a los españoles a que se registraran en el Consulado, o en caso contrario se les consideraría desafectos y sospechosos de comunistas. En segundo lugar la toma de posiciones en torno a la Junta Nacionalista y al afianzamiento progresivo de la Falange y las JONS. Por último la negativa de Avilés a aceptar el resultado de las elecciones a Junta Directiva de la SEBL para el año de 1938 porque la presidía Díaz Ufano y otros «indeseables». La reacción y actuación de Pinilla, trascendió el protocolo y se convirtió el eje de una trama que traspasaría los límites de la representación para implicar a actores importantes de la colectividad y a los responsables de la Junta de Burgos.

En una trayectoria sembrada de incidencias el autoritarismo de Avilés se pondría una vez más de manifiesto cuando el 2 de agosto de 1936, en una decisión que atentaba contra la línea de flotación del consenso establecido al interior de la elite de la colonia, enviaba una nota a los presidentes de las tres asociaciones españolas para que presentaran una lista de socios, con sus firmas y direcciones, afirmando que acataban la autoridad de la Junta de Burgos. Quedarían excluidos, «los que opusieran cualquier distingo, quienes serán considerados por esta Legación como declarados o embozados comunistas» ${ }^{32}$. Los demás españoles residentes en Lima debían suscribir la misma declaración, bien por escrito o presentándose personalmente en el Consulado, que a tal efecto permanecería abierto hasta las 7 de la tarde del sábado 8 de agosto para el registro de «españoles nacionalistas de todas las ideologías que afirman una España Libre y Soberana de sus destinos, y a su vez repudian categóricamente las teorías comunistas y anarcosindicalistas ${ }^{33}$.

La instrucción se hizo extensiva a todo el Perú, y hubo colectivos que respondieron en bloque y entusiásticamente, caso de la colonia de Arequipa. También en Lima la contestación fue positiva, pero no unánime. Avilés tomó nota de los nombres de «siete españoles de significación que cobardemente rehusaron adherirse a la Junta de Burgos» ${ }^{34}$. Uno de ellos era Aurelio Díaz Ufano, quien en contra de lo que denunciaba Avilés, sí se alineó del lado nacionalista, pero en un gesto de afirmación de su posición hegemónica y de abierto desafío, se negó a plegarse y a seguir el procedimiento impuesto por el ministro.

La brecha no haría sino abrirse, como quedaría patente en diciembre de 1937, con motivo de la llegada de la Embajada político-cultural nacionalista

32 El Comercio. Lima, lunes, 3 de agosto de 1936.

33 El Comercio. Lima, viernes 7 de agosto de 1936.

34 Legación de España. Lima. Perú, núm. 19. Segundo Año Triunfal. Avilés al Ministro de Estado, Excmo. General conde de la Jordana. 12 de marzo de 1938. AMAE. P. 309. Exp. 22407. 
enviada por Franco, y en relación con la formación de una Junta Nacionalista en el Perú. Cuando Fernando Valls i Taberner y José Ibáñez Martín, sus delegados, arribaron a Lima la polarización era ya un secreto a voces. Su corta pero intensa agenda (del 13 al 31 de diciembre) incluía hacer propaganda del Movimiento nacional, atraer a personalidades relevantes del Perú, fomentar la formación de instituciones que sirvieran de apoyo a Franco, y conseguir ayuda financiera. También hacer lo posible para unir a los españoles en «un solo haz» (es el término, de procedencia falangista, que utilizaría Pinilla). El instrumento había de ser la Junta Nacionalista de la que debían formar parte tres representantes de cada una de las tres principales instituciones de la colonia organizada. Por la SEBL la Junta General designó a Aurelio Díaz Ufano, el sacerdote Basilio Ayerdi y Enrique Vallvé35.

La experiencia fracasaría, según González Calleja —que sitúa a Avilés y a Pinilla en el mismo lado, distantes ambos de la Junta Nacionalista-, por la pugna entre la Junta, portavoz oficiosa de las instituciones españolas más conservadoras arraigadas en la vida social limeña, y la Falange en ascenso, liderada por elementos más pujantes y radicales. Plantea que Avilés era «consciente del poder económico y la influencia política oculta tras las páginas de iArriba España!, órgano de la Junta Nacionalista Española del Perú» y durante meses renunció a imponer una pauta única de acción política e hizo llamamientos a la unidad de los nacionalistas. En los números localizados de la revista apenas se pone al descubierto, y desde luego no con nombres y apellidos, la rivalidad entre la Junta Nacionalista y la pujante Falange cuya cabeza visible, Herminio Santíbañez, aparecía como suscriptor protector en los dos primeros números. Avilés no figura nunca en las listas, pero sí Pinilla, el vicecónsul Bernardo Fernández y por supuesto Aurelio Díaz Ufano ${ }^{36}$. El número de suscriptores pasó de 109 en diciembre de 1937 a 142 en abril de 1938 e incluía e españoles establecidos en distintos lugares del Perú y también a peruanos. Muchos de ellos, sin solución de continuidad, pasarían a subvencionar a iUnidad!, en una cuestión de estrategia, de estar del lado de la opción más conveniente, más que de ideología.

Siguiendo las directrices llegadas desde Burgos dejaba de publicarse tras el número nueve de julio de 1938, dejando vía libre a iUnidad! Uno de sus promotores hasta el final fue el comerciante español Manuel Morales, que había

35 La entrada de Enrique Vallvé procedente de Barcelona está registrada el 5 de abril de 1935. Tenía 29 años y se dedicó al comercio. En AGN. Ministerio de Gobierno y Policía. Dirección Policía. Sección Extranjería. Registro de Inmigrantes. Libro 69.

36 Según González Calleja iArriba España! criticó ciertas actuaciones de la Falange local y la gestión sectaria de los representantes oficiosos del gobierno de Burgos, Avilés y Tiscar, Pinilla y Bernardo Fernández, y fue abruptamente clausurada en abril de 1938 después de pasar por un periodo de serias dificultades desde fines de 1937. Pero en el número seis correspondiente a ese mes de abril todavía figuran como socios protectores Pinilla y Fernández, GonzÁlEz CALLEJA, E. «El Servico Exterior de Falange y la política exterior del primer Franquismo: consideraciones previas para su investigación». Hispania, (Madrid), 186, pp. 279-307. 
sido miembro de la junta directiva de la COECP desde 1930 y en cuyo negocio de perfumería podía adquirirse el periódico ${ }^{37}$.

La imposibilidad de contar con la documentación sobre los términos precisos de las disensiones deja una línea abierta y en puntos suspensivos ${ }^{38}$. En cualquier caso pueden introducirse y perfilarse algunos elementos para el análisis en la línea de la rivalidad interna que se viene rastreando. A pesar de que le fue solicitado por Ibáñez y Valls i Taberner, a quienes recibió con todos los honores, Avilés se negaría a ocupar la presidencia de la Junta, no sólo por motivos políticos sino también porque había en ella españoles que en su momento no habían estampado su nombre en la lista de agosto de 1936. De nuevo Díaz Ufano se erigiría como elemento de la discordia ${ }^{39}$.

Pero no sólo. Otros testigos del proceso también entendieron que Avilés alimentó la desunión perjudicando gravemente a la causa nacionalista. Así se desprende del análisis de una serie de cartas que se conservan en el archivo privado de Valls i Taberner y han sido editadas por Martínez Barrios ${ }^{40}$. La intransigencia del ministro alcanzó a una de las principales órdenes religiosas establecidas en el Perú, la de los Padres Misioneros Descalzos. Cuando su provincial, el padre Buenaventura Uriarte trató, siguiendo las peticiones de la embajada nacionalista, de hacer un donativo patriótico, Avilés se negó a recibirlo esgrimiendo que la Orden no había firmado en su momento en el Libro de Oro (así llamaba el ministro al libro abierto en el Consulado) y que su acercamiento a la Junta de Burgos era tardío.

La reacción de Uriarte fue drástica. En carta fechada en Lima el 30 de diciembre de 1937 y dirigida a Valls i Taberner e Ibáñez Martín acompañaba lo que en su criterio eran pruebas incontestables de la verdadera identidad del ministro y del cónsul. El primero se mantenía aislado en la sede de la legación en Barranco divorciado de la colonia, «cuando no interviene en ella para alejar de España y entre sí a los españoles. Un Ministro que fue ayer de la Contra España y hoy convertido de la noche a la mañana en Ministro de la España

37 Además podía conseguirse en la sede de la Cámara Oficial Española de Comercio del Perú de la calle Huancavelica 110, en el Casino Español, en el comercio de Antonio Gutiérrez y en la Casa Antonio Pulido y La Esperanza, iArriba Españai año I, número 6. Lima, abril de 1938.

$38 \mathrm{Ni}$ en el Archivo del Ministerio de Asuntos Exteriores (Histórico y Renovado), ni el Archivo General de la Administración, que conserva los documentos del Servicio Exterior de Falange, ni en el Archivo de la Guerra Civil de Salamanca, ni en el Pavelló de la República de Barcelona, se han encontrado los documentos de la Junta Nacionalista y de la Falange y las Jons en el Perú. iUnidad! es la principal fuente para rastrear las actividades de la Falange, pero se ha podido comprobar que no entra en ningún momento en los entresijos de las fricciones en el seno de la representación oficial.

39 Consulado de España. Pinilla al Ministro de Estado. Lima, 12 de marzo de 1938. AMAE. P 309. Exp. 22407.

40 Varios notables de la colonia española se comunican con Valls i Taberner para expresar su lealtad y en defensa de la Junta Nacionalista. Martínez Barrios reproduce los documentos sin interpretarlos ni caracterizar a sus autores. Ahora sólo se introducen testimonios sobre Avilés y Pinilla, pero en general transmiten enrarecimiento y disensión. 
Nacionalista quiere que todos los españoles nos fiemos de él». Por su parte Pinilla «ha sido digno alumno del Instituto Libre de Enseñanza en España, al que debemos tantos males en la Madre Patria» y llegó a decir a uno de los padres descalzos que «hasta España con el tiempo tendría que hacerse comunista». Pedía a los comisionados que gestionaran ante Franco la desaparición de representantes que, «desde hace tiempo, vienen desacreditando a España y a los Españoles en el Perú» según dice Martínez Barrios.

Algunos de lo hilos de la trama se vienen elucidando en esta propuesta. Por lo que se refiere a la representación, desde luego Avilés, del lado de los ganadores, apoyó sin reserva a la Falange y JONS y, hasta su salida del Perú asistió y avaló sus actividades públicas. Al reconstruir los hechos en 1938 Pinilla criticaría ante el Ministerio de Estado la postura intolerante del ministro que se expresó en el envío de cartas hirientes a miembros de la colonia y en la falta de apoyo a iArriba Españai, revista en la que, por cierto, el cónsul colaboraría de manera continuada con la publicación por entregas en diferentes números de «El Himno de la Falange Española de las JONS» que se editaría como folleto con el título de Glosa al Himno de Falange ${ }^{41}$.

El apoyo a la Junta Nacionalista, no fue óbice para que Pinilla se sintiera cercano a la Falange. Pediría formalmente el carnet de falangista en noviembre de 1938, cuando debido a la prohibición de Avilés ya no podía presentarse públicamente como cónsul de España, y esgrimiría su condición de afiliado para que se le reconocieran sus derechos y se le restituyera en su puesto frente a la prevaricación del ministro. Aunque los dos estaban del mismo lado, el de los nacionalistas que avanzaban hacia la victoria, mantenían una disputa que fue a más y que trascendería los límites de la representación en Lima para involucrar a las más altas instancias del gobierno.

\section{LA DISTORSIÓN EN LOS ESPACIOS DE PODER. LA SOCIEDAD ESPAÑOLA DE BENEFICENCIA DE LIMA Y LA FALANGE ESPAÑOLA Y DE LAS JONS}

Además de adscripciones ideológicas y políticas había en el trasfondo una cuestión de principios, de ejercicio de la autoridad. Avilés y Pinilla se atrincheraron en sus razones acudiendo a la normativa vigente que interpretaron de acuerdo a sus intereses. El problema remitía a la relación con la elite de la colonia en la que nuevos elementos contestarían el orden establecido. Del lado de Pinilla estuvo el presidente de la SEBL y su amigo de años, Díaz Ufano; Avilés, integrado en el aparato de Falange, contó con el jefe regional Santibáñez por razones de obediencia debida.

41 Pinilla, Antonio: Glosa al Himno de Falange. Lima, Lumen, 1998. Hay que hacer notar esta circunstancia, iArriba España! no rechazó la loa de Pinilla, que por otra parte era eminentemente retórica y no planteaba argumentos políticos que podrán dar lugar a la disensión. 
La Falange fue no sólo un mecanismo de acción franquista sino también el medio utilizado por unos cuantos para, con el respaldo de los vencedores, conseguir prestigio y poder al interior de la colonia y entre ciertos sectores de la sociedad peruana. De nuevo hay que acudir a González Calleja para encontrar algunas pistas, que reconstruye a partir de las referencias documentales proporcionadas por iUnidad!, revista que hacía la crónica detallada de las actividades de Falange ${ }^{42}$. Sin embargo hay que subrayar que en sus páginas no hay atisbo de la fuerte confrontación que por entonces mantenían Avilés y Pinilla.

En su aproximación a lo que fue el Servicio Exterior de Falange Española en Iberoamérica, González Calleja se ocupa de aquellos países donde tuvo mayor arraigo, y el Perú no estuvo entre ellos. Menciona cómo la FET no fue al principio de la guerra sino una más de las organizaciones patrióticas que canalizaban el apoyo a la España nacionalista y que en Lima la Junta Nacionalista sería la que impulsaría la creación de la filial local del partido. Una vez cumplido el objetivo las Juntas Nacionalistas debían disolverse e integrarse en la nueva estructura falangista ${ }^{43}$. Y así debió ser en el Perú, salvo resistencias que no tardarían en ceder.

La cabeza visible de la Falange en Lima sería Herminio Santibáñez que había llegado recientemente al Perú (se registraba en 1927 a los 34 años) y había abierto un negocio de representación de firmas de farmacia y ferretería. Contrajo matrimonio con Consuelo Copello, de una familia de origen italiano de fortuna, que se convertiría en una activa promotora de la causa nacionalista y tendría a su cargo el Ropero Peruano Español. En agosto de 1937 fue nombrado delegado de Prensa y Propaganda y se mantuvo al margen de la Junta Nacionalista, aunque figuraría como suscriptor de los primeros números de iArriba España!44. Por orden circular de 29 de abril de 1938 la delegación de Falange en el Perú era elevada a la categoría de Jefatura Provincial y era designado jefe regional Santibáñez. Su ascenso fue saludado por Avilés y reprobado por Díaz Ufano, que el mismo día reunía de urgencia a la Junta Directiva de la SEBL, para mostrar su desacuerdo, ya que «se trataba de un español desvinculado de las instituciones de la colonia» ${ }^{45}$.

42 GonZÁlez CAlleja, E.: «La derecha...», p. 242. No remite a documentos específicos de la Falange en el Perú.

43 GonZÁlez, Calleja, E.: «El Servicio Exterior...» pp. 196-297; PÉReZ MONForT, Ricardo: Hispanismo y Falange. Los sueños imperiales de la derecha española y México. México, Fondo de Cultura Económica, 1992, pp. 79-95; PARDO, R.: Con Franco, pp. 70-74. Ambos autores, entre otros, siguen las alternativas ideológicas y organizativas del proceso desde la fundación de las Juntas de Ofensiva Nacional Sindicalista (JONS) en octubre de 1931 y de la Falange el 29 de octubre de 1933, hasta su fusión en 1934. En 1937 fueron constituidas como FET y de las JONS en el partido que debía servir de instrumento a la política franquista.

44 Las referencias proceden de fuentes diversas que incluyen su Expediente Sucesorio. La reconstrucción de su trayectoria, como de la de otros miembros de la colonia forma parte de una investigación en curso.

45 Acta de Sesiones de la SEBL, 29 de abril de 1938. 
Para entonces la caja de los truenos ya se había destapado. El detonante fue la elección de la Junta Directiva de la SEBL para el año 1938 y el resultado inmediato el cese de Pinilla por Avilés del puesto de cónsul. En el margen de un año, arrancando desde el 15 de febrero de 1938, se sucedieron primero un duro cruce de acusaciones entre el ministro y el cónsul y después las comunicaciones de ambos con instancias y hombres influyentes en el gobierno de Burgos. Tomadas en conjunto ayudan a entender ese cuadro de inestabilidad contenida, de lucha por espacios de poder, y de rivalidad personal por el ejercicio de la autoridad.

No se entendería de otro modo que un acontecimiento «menor» que se repetía cada año derivara en un enconamiento de consecuencias irreparables para la imagen y la operatividad de los agentes oficiosos del gobierno de Burgos. Todo empezó cuando el secretario de la recién nombrada Junta de la SEBL, el sacerdote Basilio Ayerdi, comunicaba simultáneamente al ministro y al cónsul (15 de febrero) el resultado de las elecciones celebradas el 30 de enero de 1938. Pinilla en un gesto de mero formulismo enviaba una nota de felicitación (17 de febrero) sin pasarla al conocimiento de Avilés que lo entendió como un acto de «indiscreción», «desobediencia», «clandestinidad»y «falta de lealtad», motivos suficientes para requerirle (11 de marzo) que presentara la dimisión en un plazo de 24 horas.

El cónsul acataría la orden «por absoluta disciplina» pero dejaría sentada una premisa que esgrimiría a lo largo del proceso: ejercía su cargo por nombramiento de la Junta Nacional de Burgos y sólo ella podía apartarle. La respuesta de Pinilla, con membrete del Consulado y misma fecha de 11 de marzo, es un compendio de «buenas maneras» en que la formalidad y las cargas de profundidad se combinan al límite de lo permitido. Ponía en antecedentes a Avilés de que en sus 23 años de carrera nunca había tenido problemas con los diplomáticos destacado en Lima y no podía admitir los calificativos con que el ministro le ofendía, tanto más cuanto en diversas ocasiones le había ayudado actuando como mediador debido a sus buenas relaciones con la cúpula de la colonia. Con su felicitación había pretendido acercar a la legación y a la SEBL gobernada por «sinceros nacionalistas a los que falta tan sólo inculcarles un poco en el espíritu de disciplina». Le pedía que reconsiderara su decisión que perjudicaba gravemente la carrera de «un nacionalista como yo, que al igual que VE lo ha dado todo por la causa de España» ${ }^{46}$.

El 12 de marzo fue de intensa actividad. En el mismo día Avilés y Pinilla se intercambiaron notas y escribieron a Burgos. El ministro ratificaba su decisión de apartar al cónsul y la concretaba formalmente,

Muy Sr. Mío, como natural consecuencia de la absoluta pérdida de confianza, depositada en VS a raíz de la desobediencia de VS a lar órdenes que yo le impar-

46 Es una nota oficial con membrete del Consulado que Pinilla seguiría utilizando en los meses siguientes a la espera de instrucciones superiores. AMAE P. 309 Exp. 22407. 
to, plenamente demostrada recientemente, y en la necesidad de prevenir desde el primer momento nuevas posibles infracciones, he resuelto prescindir desde este instante de la funesta colaboración de VE hasta tanto que la superioridad dictamine sobre su conducta; a cuyo fin se servirá VE hacer entrega del Consulado, Archivos y dependencias de esa oficina de su cargo al Sr. D. Bernardo Fernández, vicecónsul de la Nación en Lima. Dios guarde a VE muchos años ${ }^{47}$.

Pinilla acudía al ámbito de lo personal, al recuerdo del tiempo en que habían estudiado juntos y a la dramática situación en que se hallaba su madre, en manos de los rojos. En los últimos meses habían compartido momentos difíciles «en soledad, sufriendo y gozando por idénticos anhelos», rodeados de enemigos comunes que eran los enemigos de España. Y para evitar lo inevitable reconocía, "porque así lo exige la disciplina de nuestra milicia», su error al haber actuado contradiciendo las órdenes de su superior. Pero, sutilmente, advertía a Avilés que estaba incumpliendo el Reglamento de la Carrera Diplomática porque le había destituido sin informar previamente a la superioridad ${ }^{48}$.

La suerte estaba echada. Avilés no se plegaría a sus coartadas personales y reiteraba que había solicitado al gobierno su relevo en cualquier cargo en el Perú, porque con su actitud suponía un estorbo para el desempeño de la misión diplomática que le estaba encomendada.

Al tiempo y por separado, se comunicaban con el Ministerio de Estado de la Junta de Burgos, cada uno con su versión de los hechos. En la comparación de los mensajes entendemos que Avilés sale peor parado. Su discurso era más plano, centrado en la «carencia de disciplina» y en la desobediencia reiterada del cónsul que se remontaba a la cuestión de las firmas en el libro del Consulado y se extendía hasta a la felicitación a una Junta con la que, por estar formada por elementos disidentes, no mantenía relación oficial.

Pinilla fue más hábil y convincente en el empleo de armas retóricas y prácticas para ganarse al ministro Gómez Jordana ${ }^{49}$. La tesis fundamental era que Avilés era el responsable de la desunión entre los españoles, y explicaba cómo con la imposición de las firmas había aumentado las fisuras. Introducía a la Falange como un elemento a su favor en un momento crítico: cuando se pensó

47 Representación del Gobierno Nacionalista Español. Lima. Perú. Segundo Año Triunfal. Núm. 8. Barranco, 12 de marzo de 1938. AMAE P. 309 Exp. 22407.

48 Consulado de España en Lima. Al servicio de la causa nacionalista. Lima 12 de marzo de 1938. Segundo año triunfal. AMAE P. 309 Exp. 22407. Hay que notar que Avilés sigue considerándose cónsul, ya en abierta oposición a Avilés.

$49 \mathrm{La}$ consolidación de la Falange y las JONS también dejaría en España en la cuneta a organizaciones y líderes políticos. Uno de ellos sería el propio Gómez Jordana que sucumbiría ante el avance del hombre fuerte de la Falange y cuñado de Franco, Ramón Serrano Súñer. Francisco Gómez de la Jordana (1876-1944) no contaba con experiencia directa en temas de América. Fue un político experto en África durante la Dictadura de Primo de Rivera. Depurado por la República se adhirió al alzamiento de 18 de julio y fue nombrado secretario de Relaciones Exteriores el 30 de enero de 1930 (Pardo 1995: 83-87). 
en constituirla — recapitulaba - el entonces sólo delegado de Prensa y Propaganda Santibáñez trató de incorporar a los elementos disconformes. Pero una vez más Avilés intervino y capitalizó a su manera la iniciativa redactando una fórmula «que estando bien en sí, dada la manera de ser de los españoles en América, pensamos todos los que rodeábamos al ministro, menos él, que nadie firmaría».

Era la segunda vez en la que actuaba con prepotencia. Y así Pinilla comenzó a pensar de modo diferente que el ministro, porque entendía, y con él Santibáñez, que el espíritu de la Falange era «dar facilidades para unir a todos los españoles en una hermandad». Sus razones iban acompañadas de una crónica minuciosa de los acontecimientos que se sucedieron a partir de febrero de 1938 con el ánimo de proporcionar a la superioridad elementos (los suyos) para conocer la realidad y poder ponerle solución ${ }^{50}$.

A la vista de la irreductibilidad de las posiciones, la Dirección de Personal del Ministerio de Estado entendió que era imposible restablecer la armonía y planteó como posible salida el traslado del cónsul. Pero de otro lado estimó que Avilés se había excedido en sus competencias, que no incluían el cese del cónsul. Sin embargo no se tomó ninguna decisión, todo quedó en un «SE RESOLVERÁ» que dejaba a la representación en una situación ambigua. Pinilla continuaba de hecho despojado de sus funciones, sin poder asistir como cónsul a actos públicos, usar papel oficial ni entrar en las dependencias del Consulado, tampoco recibía en su sueldo el complemento de gastos de representación. El 17 de julio de 1938 Franco firmaba en Burgos el traslado de Pinilla a Glasgow, que no se concretaría. El 16 de agosto el Tribunal Seleccionador de la Carrera Diplomática, a la vista de su trayectoria y que estaba probado que a raíz del 18 de julio se había comportado como un auténtico nacionalista, acordaba que continuara en el servicio activo, aunque sin definir su situación.

El Ministerio no volvería a tomar cartas en el asunto, lo que suponía una victoria de hecho para Avilés. Pinilla permanecería en Lima, en una situación «incómoda, equívoca y humillante», figurando nominalmente entre los socios protectores de iUnidad! hasta comienzos de 1939 y asistiendo a título personal a actos nacionalistas capitalizados por la Falange. Todavía durante un tiempo las heridas permanecerían abiertas. En el «Almuerzo de la Hispanidad», acto de camaradería celebrado en el Hotel Bertolotto el 18 de septiembre de 1938 Pinilla tuvo que escuchar alusiones a cierto grupo de españoles, «de cuyo nacionalismo no nos es posible dudar, pero que persisten en mantenerse en una actitud de bandería personalista, tan en pugna con ese orden nuevo que España está tratando de crear a fuerza de tragedia y dolor». Avilés recordaba los incidentes en torno a la

50 Consulado de España. Antonio Pinilla al ME. Lima 12 de marzo de 1938. AMAE P. 309 Exp. 22407. Tanto el documento precedente de Avilés como éste llegan a través de valija diplomática y tienen sello de entrada, el de Pinilla el 23 y el de Avilés el 28 de marzo. En cualquier caso es patente que las comunicaciones funcionaban dado el breve espacio de tiempo entre el envío (12 de marzo) y la recepción. 
desaparición de iArriba España! ordenada por el jefe de gabinete de Burgos y a las censurables maniobras desarrolladas por los que trataban de atentar contra la organización falangista. Se mantenían entre los nacionalistas tres grupos: los falangistas, los abstencionistas y los disidentes, todos favorables al Caudillo, pero los últimos actuando con procedimientos «obstrucionistas» y descalificadores». Para atajar su incidencia había decidido proceder al relevo de $\operatorname{cargos}^{51}$.

Pinilla haría todavía un intento de entrevistarse con Avilés a través de la intermediación de su amigo común (y en ese momento cónsul en funciones) Bernardo Fernández que no llegó a concretarse. El último recurso era la Falange, y a su jefe Santibáñez pedía el 13 de diciembre que interviniera para acercar a dos camaradas. Concretamente le pedía poder asistir con las prebendas que como cónsul le concedía el protocolo al «Almuerzo del Plato Único» convocado para el 18 de diciembre. Era una manifestación importante porque contaría con la presencia de miembros de la oligarquía peruana y de las colonias italiana, alemana y portuguesa. Pero la jerarquía era la jerarquía, Santibáñez, siguiendo la estructura de la FET, reconocía la superioridad de Avilés y le pedía por tanto que no acudiera o de hacerlo fuera como un camarada más. Pinilla se plegó.

Una orden de 4 de febrero le destinaba a Bolivia sin haber logrado que se le rehabilitara en el Perú. Moriría súbitamente en La Paz el 3 de abril de 1939, dos días después de una victoria que no pudo disfrutar. Veinte años de dedicación apenas merecieron una columna en iUnidad!, si bien es cierto que su féretro fue transportado por camaradas y en el séquito estaba el ministro. Muy distinta fue la despedida que se organizó a Avilés en los locales de la Falange en el mes de mayo con motivo de su partida a Colombia, en reconocimiento por haber representado a España, "con estilo completamente falangista» 52 .

Fuera de escena dos de los inductores del enfrentamiento, en la cúpula de la colonia se restablecería el orden interno. Si nos atenemos a la información que proporciona su órgano de expresión la Falange no llegó a consolidarse como una organización fuerte en cuanto a vida institucional y al número y peso específico de sus militantes ${ }^{53}$. En 1939 la SEBL tendía una directiva falangista presidida por el camarada Bernardo Fernández Fernández. Pero en 1940 Díaz Ufano retomaría las riendas y, de nuevo al frente de la SEBL, recibía al primer embajador de España en el Perú Pablo Churruca y Dotres.

Los grandes de la colonia que aún mantenían una alta posición social no aparecen en las listas de socios suscriptores, que están integradas por los hijos

51 iUnidad!, 5. Lima, 1 de octubre de 1938, p. 2.

52 iUnidad!, 20-21. Lima, 1 de junio de 1939.

53 En casi todos los números de iUnidad! hay una breve información sobre la Falange en el Perú. Recoge los nombres de los nuevos camaradas, que son contadísimos, las listas de socios suscriptores, que son más breves que las de iArriba España!, y algunos aconteceres de escasa proyección. Los actos públicos se ralentizan paulatinamente y la revista se nutre en buena medida de reimpresiones y noticias de España. Es Santibáñez con colaboraciones habituales quien, junto al director Federico Pasco Font, parece mantener la continuidad de la publicación. 
de algunos de ellos y por hombres nuevos. Pareciera que la exigüa colonia española optó por dedicarse a su actividad profesional y a integrarse en el día a día del país que habían elegido para vivir.

La propuesta se detiene en 1939 y deja en puntos suspensivos cuestiones que se abren como interrogantes para avanzar en el conocimiento de una coyuntura sobre la que todavía planean sombras. El trazado de las trayectorias personales y profesionales de algunos actores clave que ocuparon puestos de responsabilidad, tanto en la representación oficial como en la cúpula de la colonia española en Lima, y la presentación de los conflictos internos generados por la disputa de espacios de poder, ofrecen líneas inéditas acerca un modelo de perfiles excepcionales en el contexto iberoamericano. 